\title{
Radiofrequency ablation following artificial ascites and pleural effusion creation may improve outcomes for hepatocellular carcinoma in high-risk locations
}

\author{
Yi-Chung Hsieh ${ }^{1} \cdot$ Jenny L. Limquiaco ${ }^{1,2} \cdot$ Chen-Chun Lin ${ }^{1} \cdot$ Wei-Ting Chen ${ }^{1} \cdot$ Shi-Ming Lin ${ }^{1}$
}

Published online: 20 November 2018

(C) The Author(s) 2018

\begin{abstract}
Purpose To investigate the outcomes of radiofrequency ablation (RFA) following artificial ascites (AA) and artificial pleural effusion (AP) creation for hepatocellular carcinoma (HCC) in high-risk locations.

Materials and methods Eligible patients were divided into 2 study periods (non-AAAP and AAAP groups) with AAAP performed in the latter period. Local tumor progression, primary technique effectiveness and complications were compared between patients with and without AAAP. Cumulative probability of local tumor progression and overall survival were estimated with Kaplan-Meier curves.

Results One hundred thirty-eight patients with 195 tumors were evaluated. AAAP was performed in 48 patients with 76 tumors. Local tumor progression rates at 12 and 24 months were $9.3 \%$ and $22.2 \%$ in the non-AAAP group versus $5.5 \%$ and $9 \%$ in the AAAP group $(p<0.0001)$. Primary technique effectiveness was achieved in $76.5 \%$ of the non-AAAP group versus $89.5 \%$ of the AAAP group $(p=0.046)$. Night $(7.6 \%)$ major complications occurred in the non-AAAP group and 2 $(2.6 \%)$ cases occurred in the AAAP group. Therapy-oriented severity grading system after RFA was lower in the AAAP group $(p=0.02)$. Overall survival rates at 12 and 24 months were $85.6 \%$ and $77.7 \%$ in the non-AAAP group versus $97.2 \%$ and $89.7 \%$ in the AAAP group $(p=0.033)$.

Conclusion RFA following AA and AP for high-risk located HCC may improve outcomes.
\end{abstract}

Keywords Artificial ascites · Artificial pleural effusion · Hepatocellular carcinoma · High-risk location · Radiofrequency ablation

\section{Introduction}

Radiofrequency ablation (RFA) has been proven to be a first-line curative treatment for very early stage or unresectable early stage hepatocellular carcinoma (HCC) [1-6]. It has gained wide acceptance for the treatment of $\mathrm{HCC}$

Yi-Chung Hsieh and Jenny L. Limquiaco have contributed equally to this article.

Shi-Ming Lin

lsmpaicyto@cgmh.org.tw; 1smpaicyto@gmail.com

1 Division of Hepatology, Department of Gastroenterology and Hepatology, Liver Research Unit, Chang Gung Memorial Hospital and Chang Gung University, Linkou, Taiwan

2 Division of Gastroenterology, Department of Medicine, University of the Philippines-Philippine General Hospital, Manila, Philippines because of its effectiveness, safety, predictable ablation extent, and minimal invasiveness [7-11]. However, sonography-guided percutaneous RFA for high-risk located tumors is technically challenging because of poor tumor visualization or suboptimal electrode path due to overlapped lungs or ribs. There is also a substantial risk of thermal injury to surrounding structures including the diaphragm and gastrointestinal (GI) tract $[12,13]$. Therefore, an optimal outcome after RFA may be compromised due to incomplete ablation or injury to nearby structures $[14,15]$. Several strategies have been employed as an adjunct to percutaneous RFA for tumors in problematic locations. These include the use of artificial fluid, combined use of ethanol injection and RFA, low power RFA $(\leq 120 \mathrm{~W})$, balloon catheter interposition, different radioimaging guided modalities, and laparoscopic or open approaches [16-27]. 
The induction of artificial intraperitoneal and intrapleural fluid was first utilized to reduce the diaphragmatic injury during RFA $[17,19,28]$. However, large-scale survival analysis of artificial ascites (AA) and artificial pleural effusion (AP) creation during percutaneous RFA is scarce. Consecutive adult patients with HCC receiving RFA have remained cared in our hospital as ablation techniques for high-risk located tumors have continued to evolve. This allows us an ideal setting to assess the outcome of artificial intraperitoneal and intrapleural fluid creation and to investigate the proposition that this technique could have had an impact on patient's outcomes.

\section{Materials and methods}

\section{Patients}

This retrospective study included 138 consecutively registered patients with HCC located in high-risk locations undergoing RFA in Chang Gung Memorial hospital, Linkou Medical center between January 2004 and June 2008. The indication criteria of RFA for HCC were as follows: (1) tumors were surgically unresectable or the patient voluntarily chose nonsurgical treatment, (2) total serum bilirubin concentration was lower than $3 \mathrm{mg} / \mathrm{dL}$, (3) platelet count was $50 \times 10^{9} / \mathrm{L}$ or greater, (4) international normalized ratio (INR) was $<1.5$, and (5) no extrahepatic metastasis or vascular tumor invasion was observed. Patients who underwent transarterial chemoembolization (TACE) and other forms of loco-regional treatment within 1 year before the intended RFA were excluded. Informed consents were obtained from all patients prior to RFA and the creation of AAAP.

HCC was diagnosed through the presence of a hypervascular liver mass in the arterial phase of a dynamic imaging study [computed tomography (CT) or magnetic resonance imaging (MRI)] with contrast washout during the portal or delayed phase, or cytologic or histopathologic findings. HCC in high-risk locations was defined as those located $<5 \mathrm{~mm}$ of vital structures, such as the liver capsule, heart, lung, gallbladder, kidney, GI tract, or diaphragm. The Edmondson and Steiner classification was used to grade HCC [29]. Baseline demographics, biochemical tests, serum alpha-fetoprotein (AFP), and RFA settings were recorded. Patients were analyzed according to two time periods: prior to and after the adoption of AAAP creation for tumors in high-risk locations.
Between January 2004 and September 2006 study period (Non-AAAP group)

Percutaneous RFA was performed under real-time sonographic guidance (Aplio SSA-700A, Toshiba, Japan) in a large 3000 bed tertiary referral center by three interventional hepatologists who had more than 10 years of experience in performing interventional procedures and surpassed the critical threshold of learning curve [9]. Either one of three devices was used: an internally cooled electrode with a $3 \mathrm{~cm}$ uninsulated tip (Cool-tip radiofrequency system, Radionics), an expandable electrode with 10-12 tines extending to $2-4 \mathrm{~cm}$ in diameter with impedance monitoring (LeVeen electrode, RadioTherapeutics), and an expandable electrode with 9 tines extending to $3-5 \mathrm{~cm}$ in diameter with temperature monitoring (Starburst XL, RITA Medical Systems). The selection of the type of electrode was dependent on the operator's preference or health insurance restrictions. The internally cooled electrode and the expandable electrode with temperature monitoring were operated according to the manufacturers' instructions. The expandable electrode with impedance monitoring was operated according to an interactive algorithm described elsewhere [30]. Multiple overlapping ablations were performed as appropriate to achieve a 5-10 $\mathrm{mm}$ ablative safety margin around the tumor when feasible. Electrode track thermocoagulation was routinely performed with a power of 20 watts on withdrawal. A standard protocol for conscious sedation consisting of $30 \mathrm{mg}$ meperidine hydrochloride (Demerol USP) and $3 \mathrm{mg}$ midazolam (Dormicum Roche) was administered intravenously prior to ablation. These doses were then titrated to achieve an adequate comfort level throughout the procedure. Local anesthesia was applied with $1 \%$ lidocaine hydrochloride along the planned puncture site. Occasionally, combined percutaneous ethanol injection (PEI) and RFA were done in tumors close to blood vessels to reduce the heat sink effect with the use of 21-22 gauge, $15-20 \mathrm{~cm}$ long needle to inject $1-5 \mathrm{~mL}$ of $99.5 \%$ ethanol into the tumor while the RFA electrode was positioned 5-10 $\mathrm{mm}$ away from the PEI needle [20]. We routinely did follow-up sonography the following day to see if any complications appeared, and gave cefuroxime $750 \mathrm{mg}$ IV q12 h for 1-2 days after RFA to avoid infection.

\section{Between October 2006 and June 2008 period (AAAP group)}

A customized strategy of ultrasound-guided AA and AP creation for tumors in high-risk locations was adopted in this unit since October 2006. An 18 gauge needle was inserted gently through the intercostal space to position its tip between the costal and diaphragmatic parts of the parietal pleura to create AP for tumors abutting the 
diaphragm and subcapsular in location. The needle was considered correctly in place if there was no resistance during the test injection of $20 \mathrm{ml}$ water containing $5 \%$ dextrose (D5 W). Infusion of D5 W was continued until adequate separation of the tumor and adjacent structures had been achieved as evidenced by an at least 5-10 $\mathrm{mm}$ of fluid space by real-time ultrasonography. AA was induced for tumors located in close proximity to vital structures by inserting the 18 gauge needle just in front of the surface of the liver. For tumors close to gallbladder, an initial $20 \mathrm{~mL}$ of D5 W solution was injected into the gallbladder fossa with a 20-22 gauge needle. This technique allows separation of the liver tissue from the gallbladder cystic plate. For tumors located near the GI tract, the patient is placed in the right oblique lateral position to allow bowels to move away from the liver. Successful separation was defined as creation of an at least 5-10 $\mathrm{mm}$ fluid space between the lung and the diaphragm for AP or between the liver surface and the adjacent organs for AA in order to visualize the index tumor or/and make the radiofrequency electrode path feasible. RFA was started as soon as the fluid space was made and before the fluid settled down into the dependent portion of the abdomen.

\section{Follow-up protocol}

A dynamic imaging study (CT or MRI) was performed for all patients 4 weeks after RFA for assessment of the completeness of ablation. A complete ablation of the tumor was defined as an area of low attenuation on contrast-enhanced CT or MRI that encompassed the area of the index tumor with no nodular peripheral enhancement on dynamic studies. Dynamic imaging studies, liver function tests, and AFP measurement were repeated every 3-6 months after achievement of complete ablation.

\section{Study endpoints}

The primary endpoint of this study was local tumor progression. Local tumor progression was defined as the appearance of tumor foci at the edge of the ablation zone after at least one dynamic follow-up image has documented the index tumor was previously completely. The secondary endpoints were primary technical effectiveness, procedurerelated complications and overall survival. Primary technical effectiveness was defined as complete ablation of the index tumor after one or more RFA sessions. These endpoints were mostly based on the document set by the International Working Group on Imaging-Guided Tumor Ablation [31]. The definitions recently outlined by the Society of Interventional Radiology were used for major and minor complications [32]. Major complications cause hospitalization for therapy, an unplanned increase in the level of care, prolonged hospitalization, permanent adverse sequelae, or death; minor complications cause no sequelae, nominal therapy, or a short hospital stay for observation. Objective evaluation of post-procedural complications was categorized based on the therapy-oriented severity grading system (TOSGS) (Appendix) [33].

\section{Statistical analysis}

All index tumors were assessed for local tumor progression, primary technical effectiveness and complications between two study periods. The survival rates of two groups were compared with at least 6-month follow-up period. Patients with multiple index tumors in whom not all tumors were managed with RFA were excluded from the survival analysis. Continuous and categorical variables were analyzed with the independent student $t$ test or MannWhitney $U$ test and Chi square test or Fisher's exact test, respectively. Cumulative probability of local tumor progression and overall survival were estimated with KaplanMeier curves. Variables with $p \leq 0.1$ were included in the multivariate analysis. Cox regression analysis with forward logistic regression was used to model independent predictors of local tumor progression and survival. A value of $p<0.05$ was considered significant. All statistical analyses were performed with statistical software (SPSS V.13).

\section{Results}

A total of 138 patients with 195 tumors underwent RFA during the study period. Seventy HCC patients were histologically proven while the remaining sixty-eight patients were diagnosed using 2 positive imaging studies. There were 119 tumors in the non-AAAP group and 76 tumors in the AAAP group. Patients were comparable in age, sex, tumor size, segment and special location (Table 1). One hundred and one nodules $(51.8 \%)$ were subcapsular and 94 nodules $(48.2 \%)$ were adjacent to vital organs. AA was created in $60(78.9 \%)$ tumors, AP in $13(17.1 \%)$ tumors and both AA and AP in 3 (3.9\%) tumors. Successful separation was achieved in 74/76 (97.4\%) of cases for $23 \pm 9 \mathrm{~min}$, and created a $2.6 \pm 0.4 \mathrm{~cm}$ fluid space. The mean amount of artificial intraperitoneal or intrapleural fluid infused was 822 (range 350-1750) $\mathrm{ml}$.

\section{Local tumor progression}

Local tumor progression was evaluated exclusively among treatment-naïve nodules. The AAAP group had less local tumor progression than the non-AAAP one $(28.1 \%$ vs $48.7 \%, p=0.036$ ). About $80 \%$ and $20 \%$ patients received RFA and TACE after local tumor progression, respectively. 
Table 1 Patient and tumor characteristics

\begin{tabular}{|c|c|c|c|}
\hline & Non-AAAP group 90 patients, 119 tumors & AAAP group 48 patients, 76 tumors & $P$ value \\
\hline Age in years & $67.4 \pm 11.8$ & $65.8 \pm 11.2$ & 0.270 \\
\hline Male gender & $48(53.3 \%)$ & $38(79.2 \%)$ & 0.073 \\
\hline Etiology of liver disease & & & 0.198 \\
\hline Hepatitis B & $37(41.1 \%)$ & $21(43.8 \%)$ & \\
\hline Hepatitis C & $33(36.7 \%)$ & $11(22.9 \%)$ & \\
\hline Others & $20(22.2 \%)$ & $16(33.3 \%)$ & \\
\hline Tumor diameter & & & 0.678 \\
\hline$<3 \mathrm{~cm}$ & $74(62.2 \%)$ & $44(57.9 \%)$ & \\
\hline$\geq 3 \mathrm{~cm}$ & $45(37.8 \%)$ & $32(42.1 \%)$ & \\
\hline Tumor grade & & & 0.164 \\
\hline I-II & $67(59.8 \%)$ & $35(55.6 \%)$ & \\
\hline III-IV & $45(40.2 \%)$ & $28(44.4 \%)$ & \\
\hline Segment & & & 0.373 \\
\hline Segment 2 & $2(1.7 \%)$ & $5(6.6 \%)$ & \\
\hline Segment 3 & $6(5.0 \%)$ & $2(2.6 \%)$ & \\
\hline Segment 4 & $11(9.2 \%)$ & $11(14.5 \%)$ & \\
\hline Segment 5 & $21(17.6 \%)$ & $10(13.2 \%)$ & \\
\hline Segment 6 & $28(23.5 \%)$ & $21(27.6 \%)$ & \\
\hline Segment 7 & $23(19.3 \%)$ & $13(17.1 \%)$ & \\
\hline Segment 8 & $28(23.5 \%)$ & $14(18.4 \%)$ & \\
\hline Special location & & & 0.852 \\
\hline Subcapsular & $61(51.3 \%)$ & $40(52.6 \%)$ & \\
\hline Proximity to vital organs & $58(48.7 \%)$ & $36(47.4 \%)$ & \\
\hline AFP (ng/ml) & & & 0.801 \\
\hline$<200$ & $78(86.7 \%)$ & $40(83.3 \%)$ & \\
\hline$>200$ & $12(13.3 \%)$ & $8(16.7 \%)$ & \\
\hline ALT (U/L) & $62.7(9-358)$ & $53.4(10-483)$ & 0.085 \\
\hline Total bilirubin (mg/dl) & $1.1 \pm 0.6$ & $1.0 \pm 0.7$ & 0.331 \\
\hline Albumin (g/dl) & $3.6 \pm 0.6$ & $3.7 \pm 0.7$ & 0.166 \\
\hline INR & $1.2 \pm 0.2$ & $1.2 \pm 0.2$ & 0.281 \\
\hline Platelet $\left(10^{9} / \mathrm{L}\right)$ & $109.2 \pm 48.6$ & $107.6 \pm 57.2$ & 0.276 \\
\hline Creatinine (mg/dL) & $1.4 \pm 1.0$ & $1.1 \pm 0.4$ & 0.902 \\
\hline Child-Pugh classification & & & 0.150 \\
\hline A & $72(80.0 \%)$ & $42(89.4 \%)$ & \\
\hline B & $18(20.0 \%)$ & $5(10.6 \%)$ & \\
\hline Treatment-naive & $57(63.3 \%)$ & $28(58.3 \%)$ & 0.187 \\
\hline RFA electrode & & & 0.067 \\
\hline Internally cooled & $113(95.0 \%)$ & $67(88.2 \%)$ & \\
\hline Expandable electrodes & $6(5.0 \%)$ & $9(11.8 \%)$ & \\
\hline
\end{tabular}

$A A A P$ artificial ascites/artificial pleural effusion, $A F P$ alpha-fetoprotein, $A L T$ alanine aminotransferase, INR international normalized ratio, $R F A$ radiofrequency ablation

The cumulative incidence of local tumor progression among nodules in the AAAP group was statistically lower than the non-AAAP group with $0 \%, 5.5 \%$, and $9.0 \%$ at 6 , 12 , and 24 months versus $3 \%, 9.3 \%$, and $22.2 \%$, respectively $(p<0.0001)$ (Fig. 1). Tumor size $>4 \mathrm{~cm}$ (adjusted
HR 3.4, 95\% CI 1.6-7.6) and failure of achieving complete ablation (adjusted HR 5.0, 95\% CI 2.5-10.0) were associated with local tumor progression (Table 2). 
Fig. 1 Cumulative local tumor progression rates in the preAAAP era (non-AAAP group) and AAAP era (AAAP group). $A A A P$ artificial ascites/artificial pleural effusion

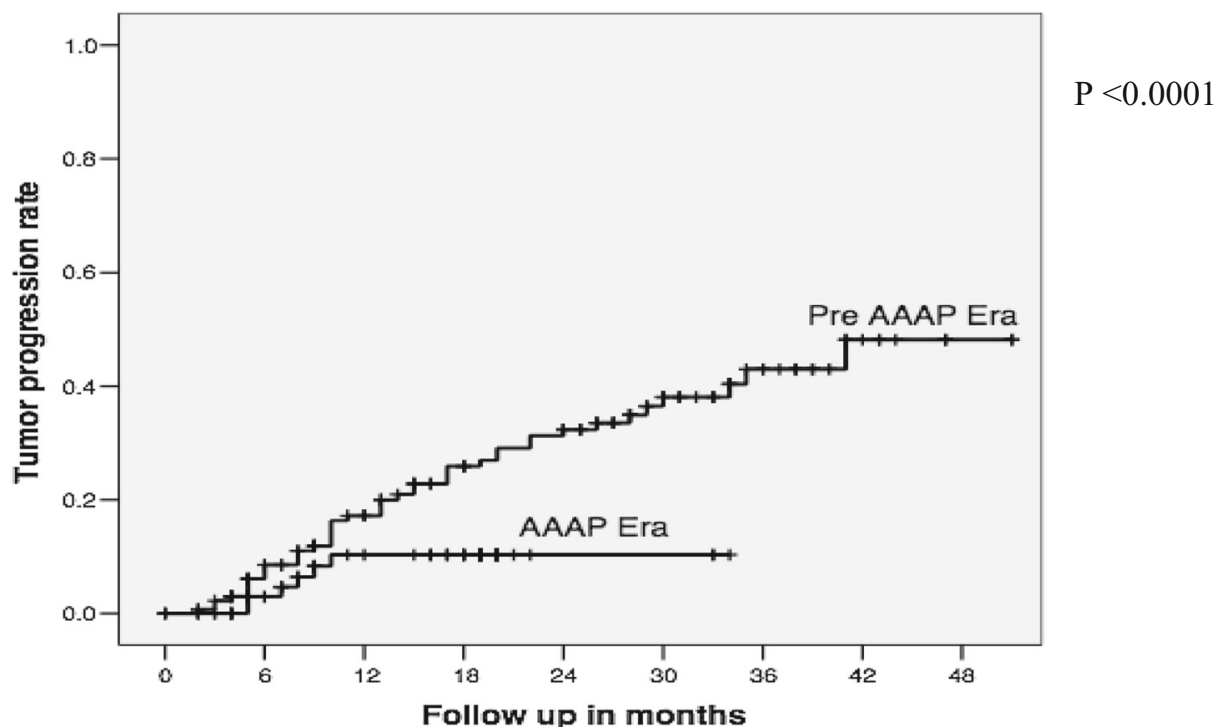

Number of patients at risk

Pre-AAAP era 102

93

AAAP era

48

40

34

31

$25 \quad 5$

Table 2 Univariate and multivariate analyses of factors associated with local tumor progression

\begin{tabular}{|c|c|c|c|}
\hline & \multirow{2}{*}{$\begin{array}{l}\text { Univariate } \\
\text { analysis } \\
P \text { value }\end{array}$} & \multicolumn{2}{|c|}{ Multivariate analysis } \\
\hline & & $\mathrm{HR}(95 \% \mathrm{CI})$ & $P$ value \\
\hline $\begin{array}{l}\text { Ablation } \\
\text { time }>12 \mathrm{~min}\end{array}$ & 0.28 & & \\
\hline Multiple tumors & 0.14 & & \\
\hline Subcapsular location & 0.20 & & \\
\hline Tumor size $>4 \mathrm{~cm}$ & 0.001 & $3.4(1.6-7.6)$ & 0.002 \\
\hline Incomplete ablation & $<0.001$ & $\begin{array}{l}5.0 \\
\quad(2.5-10.0)\end{array}$ & $<0.001$ \\
\hline
\end{tabular}

$H R$ hazard ratio; $C I$ confidence interval

\section{Primary technique effectiveness}

Primary technique effectiveness for the AAAP group was statistically significant compared with the non-AAAP group $(88.0 \%$ versus $78.4 \%, p=0.046)$. There was no significant difference in other treatment parameters between two groups (Table 3 ).

\section{Complications}

A total of 195 tumors in 138 patients were treated with RFA. Differences in major complications (7.6\% vs $2.6 \%$, $p=0.565)$ and minor complications (10.9\% vs $15.8 \%$, $p=0.173$ ) between two groups were not significant (Table 4). There were no procedure-related deaths. Two patients developed liver abscess formation after 1 month and percutaneous drainage was performed in one of them. The incidence of electrode track seeding was $1.5 \%$. In two patients, cancer seeding along the presumed electrode tract was identified at CT obtained 4 months and 23 months after RFA, respectively. One case of tumor seeding was histologically proven after surgical exploration as a consequence of tumor rupture after RFA. One patient developed acute cholecystitis 3 days after RFA and with resolution of symptoms after cholecystectomy. Clinical assessment of post-procedural complications by TOSGS showed that the AAAP group had a significantly lower magnitude of complications compared to the non-AAAP group $(p=0.02)$. Four patients with complications in the non-AAAP group (17.4\% vs $0 \%)$ required surgical intervention while the entire AAAP group were managed conservatively. In the AAAP group, there was spontaneous absorption of AA and AP within 3-5 days after creation. The median hospitalization stay was 6 (range 2-26) days.

\section{Overall survival}

Twenty-five patients in the non-AAAP group and two patients in the AAAP group died after a median follow-up period of 25.1 (range 3.8-54.1) months [28.3 (range 3.8-54.1) months in the non-AAAP group vs 17.8 (range 
Table 3 Comparison of treatment parameters and endpoints between non-AAAP and AAAP groups

\begin{tabular}{lll}
\hline & $\begin{array}{l}\text { Non-AAAP group 90 patients, } 119 \\
\text { tumors }\end{array}$ & $\begin{array}{l}\text { AAAP group } 48 \text { patients, } 76 \\
\text { tumors }\end{array}$ \\
\hline $\begin{array}{l}\text { RFA duration (minutes per tumor) } \\
\text { Mean number of overlapping ablation per tumor per }\end{array}$ & $11.1 \pm 4.3$ & $18.6 \pm 10.2$ \\
session (range) & $1.7(1-4)$ & $1.8(1-5)$ \\
HCC $<3 \mathrm{~cm}$ & & \\
$\leq 3$ ablations & $79(100 \%)$ & $47(97.9 \%)$ \\
$>3$ ablations & $0(0 \%)$ & $1(2.1 \%)$ \\
HCC $\geq 3 \mathrm{~cm}$ & & $18(64.3 \%)$ \\
$\leq 3$ ablations & $35(87.5 \%)$ & $10(35.7 \%)$ \\
$>3$ ablations & $5(12.5 \%)$ & $35(72.9 \%)$ \\
Complete ablation after 1 session & & $21(75 \%)$ \\
HCC $<3$ cm & $62(78.5 \%)$ & $44(88.0 \%)$ \\
HCC $\geq 3$ cm & $27(67.5 \%)$ & $16(28.1 \%)$ \\
Primary technique effectiveness & $76(78.4 \%)$ & 0.187 \\
Local tumor progression & $55(48.7 \%)$ & 0.0001 \\
\hline
\end{tabular}

$A A A P$ artificial ascites/artificial pleural effusion, $R F A$ radiofrequency ablation, $H C C$ hepatocellular carcinoma

Table 4 Complications after RFA

\begin{tabular}{|c|c|c|c|}
\hline Complications & Non-AAAP group & AAAP group & $P$ value \\
\hline Major & $9(7.6 \%)$ & $2(2.6 \%)$ & 0.565 \\
\hline Abscess & 2 & 0 & \\
\hline Tract seeding & 2 & 1 & \\
\hline Tumor rupture & 1 & 1 & \\
\hline Acute cholecystitis & 1 & 0 & \\
\hline Complicated pleural effusion & 2 & 0 & \\
\hline Thermal GIT injury & 1 & 0 & \\
\hline Minor & $13(10.9 \%)$ & $12(15.8 \%)$ & 0.173 \\
\hline Pleural effusion & 9 & 7 & \\
\hline Ascites & 0 & 2 & \\
\hline PV thrombosis & 2 & 0 & \\
\hline IHD dilatation & 3 & 0 & \\
\hline Atelectasis & 0 & 1 & \\
\hline Postablation pyrexia & 0 & 2 & \\
\hline Therapy-oriented severity grading system & & & 0.020 \\
\hline Grade 1: no specific intervention & 19 & 12 & \\
\hline Grade 2: drug therapy & 0 & 2 & \\
\hline Grade 3a: invasive therapy without general anesthesia & 0 & 0 & \\
\hline Grade $3 \mathrm{~b}$ : invasive therapy under general anesthesia & 4 & 0 & \\
\hline Grade 4a: single organ dysfunction in ICU & 0 & 0 & \\
\hline Grade 4b: multiorgan dysfunction in ICU & 0 & 0 & \\
\hline Grade 5: death & 0 & 0 & \\
\hline
\end{tabular}

$A A A P$ artificial ascites/artificial pleural effusion, $G I T$ gastrointestinal tract, $P V$ portal vein, $I H D$ intrahepatic duct, $I C U$ intensive care unit

5.2-33.7) months in the AAAP group]. No patient died as a direct result of RFA and none died within 30 days of the last RFA session. The causes of death were liver failure due to sepsis $(n=8)$, esophageal or gastric variceal bleeding $(n=6)$, massive pleural effusion/chest infection $(n=5)$, portal vein thrombosis $(n=3)$, hepatorenal syndrome 
$(n=3)$, and progressive encephalopathy $(n=2)$. Cumulative probability of overall survival at 6,12 and 24 months was $94.4 \%, 85.6 \%$ and $77.7 \%$ in the non-AAAP group compared to $100 \%, 97.2 \%$ and $89.7 \%$ in the AAAP group ( $p=0.033$ ) (Fig. 2). Tumor size $\geq 3 \mathrm{~cm}$ (adjusted HR: 2.7, 95\% CI: 1.2-5.9) and creation of AAAP (adjusted HR $0.1,95 \%$ CI $0.01-0.95$ ) were associated with overall survival (Table 5).

\section{Discussion}

This study demonstrated that RFA following AA and AP creation may improve outcomes in terms of local tumor progression, primary technique effectiveness, degree of procedure-related complications and overall survival for HCC in high-risk locations. This has important clinical implications since tumors in high-risk locations are associated with poor prognosis [17, 19, 28, 34-36].

The creation of AAAP achieves two goals in promoting a favorable clinical outcome. Firstly, it decreased the magnitude of procedure-related complications as evidenced by a lower score of TOSGS. The hemodynamic instability and multi-organ failure brought about by mechanical and septic peri-procedural complications can lead to a cascade of events that can compromise hepatic functional reserve and survival [15]. Intraperitoneal and intrapleural infusion act as a thermal blanket by ensuring adequate separation of the ablation zone from the adjacent structures. The non-ionic nature of dextrose water rather than normal saline as an instillation also offers an ideal buffer against heat injury. Saline, an ionic fluid, can conduct heat away from the ablation zone and increase the electrical conductivity to adjacent structures [37]. AAAP also improves the sonic window allowing the operator to place the electrodes in a safe manner. Conceptually, ascitic fluid has been thought to reduce the "tamponade" effect from the opposing parietal peritoneum against the liver and to eliminate thrombogenic substances at the puncture site, but none of the AAAP patients developed procedure-associated hemoperitoneum in our study [14]. Electrode tract thermocoagulation can induce a hemostatic effect thereby accounting for the rarity of this type of complication. Diaphragmatic and biliary tract heat injuries have also been reported sporadically after RFA for subcapsular tumors [38]. However, no patient complained of symptoms associated with diaphragmatic paresis or biliary tract sequelae in our study. Thermal injury to adjacent bile ducts remains a challenge because bile flow is slow and has little cooling effect in contrast to blood flow. Its influence on long-term prognosis remains to be elucidated. Secondly, AAAP creation improved ultrasonographic image clarity allowing the operators to perform multiple electrode placements to ensure complete ablation of larger tumors which is crucial to delay tumor progression. Although multiple electrode placements have been correlated with electrode tract seeding in up to $12 \%$ of cases in the previous report, the rate of electrode tract seeding for RFA in our cohort was low at $1.5 \%$ [15]. In the context of routine thermocoagulation, the benefit of improved prognosis resulting from
Fig. 2 Overall survival rates in the pre-AAAP era (non-AAAP group) and AAAP era (AAAP group). AAAP artificial ascites/ artificial pleural effusion

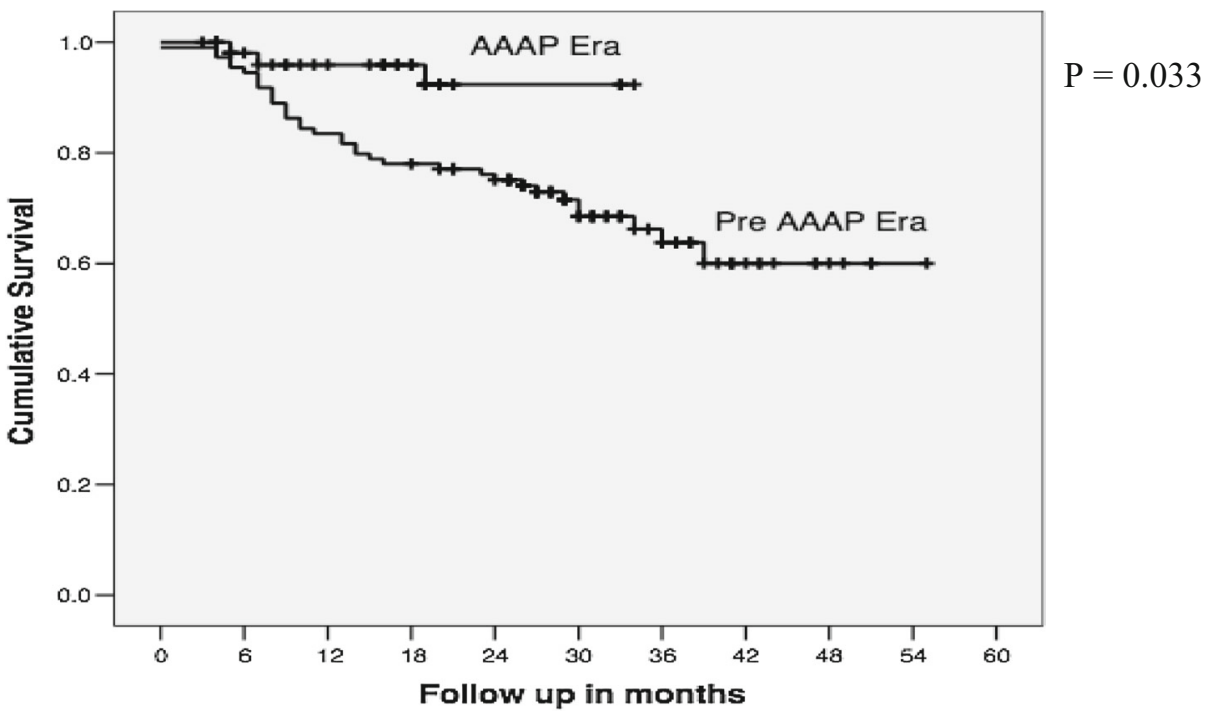

Numer of patients at risk

$\begin{array}{lllllllllll}\text { Pre-AAAP era } & 89 & 85 & 76 & 72 & 68 & 42 & 25 & 11 & 4 & 1 \\ \text { AAAP era } & 47 & 38 & 33 & 26 & 10 & 4 & & & \end{array}$


Table 5 Univariate and multivariate analyses of factors associated with overall survival

\begin{tabular}{|c|c|c|c|c|}
\hline & \multirow[t]{2}{*}{ No. of patients or tumors } & \multirow{2}{*}{$\begin{array}{l}\text { Univariate analysis } \\
P \text { value }\end{array}$} & \multicolumn{2}{|c|}{ Multivariate analysis } \\
\hline & & & HR $(95 \%$ CI $)$ & $P$ value \\
\hline Male sex & 86 & 0.45 & & \\
\hline Age $\geq 65$ years & 88 & 0.49 & & \\
\hline Multiple tumors & 42 & 0.60 & & \\
\hline $\mathrm{AFP} \geq 200 \mathrm{ng} / \mathrm{ml}$ & 20 & 0.03 & & 0.214 \\
\hline Local tumor progression & 51 & $<0.001$ & & 0.081 \\
\hline Child-Pugh class B & 23 & 0.050 & & 0.081 \\
\hline Tumor size $\geq 3 \mathrm{~cm}$ & 53 & 0.02 & $2.7(1.2-5.9)$ & 0.014 \\
\hline AAAP group & 90 & 0.017 & $0.1(0.02-0.95)$ & 0.044 \\
\hline
\end{tabular}

$H R$ hazard ratio, $C I$ confidence interval, $A F P$ alpha-fetoprotein, $A A A P$ artificial ascites/artificial pleural effusion

Table 6 Summary of studies involving the use of AAAP for HCC in high-risk locations

\begin{tabular}{|c|c|c|c|c|c|c|c|}
\hline Source & $\begin{array}{l}\text { Patient } \\
\text { No. }\end{array}$ & $\begin{array}{l}\text { AA or } \\
\text { AP }\end{array}$ & $\begin{array}{l}\text { Follow-up } \\
\text { period (months) }\end{array}$ & $\mathrm{TE}$ & Complication & LTP & Overall survival \\
\hline Chen et al. [49] & 215 & AA & NA & $91.6 \%$ & $3.2 \%$ & $8.4 \%$ & $\begin{array}{l}81.6 / 63.8 / 53.6 \%(1 / 2 / \\
3 \text { years })\end{array}$ \\
\hline Kang et al. [50] & 160 & AA & 52.5 & NA & NA & $\begin{array}{l}17.1 \% / 27.6 \% / 35.2 \% / \\
35.2 \%(1 / 2 / 4 / 6 \text { years })\end{array}$ & NA \\
\hline Koda et al. [16] & 23 & AP & 10.6 & $88 \%$ & NA & $4.5 \%$ & NA \\
\hline Kondo et al. [18] & 52 & AA & NA & $96 \%$ & $1.9 \%$ & $3.6 \%$ & NA \\
\hline Kondo et al. [19] & 587 & $\mathrm{AP}$ & 33.6 & NA & $3.7 \%$ & $76 \%$ & NA \\
\hline Nam et al. [51] & 28 & AA & 37.4 & NA & $0 \%$ & $26.7 \%$ & NA \\
\hline Rhim et al. [17] & 25 & AA & 6 & $96 \%$ & NA & $16 \%$ & NA \\
\hline Teratani et al. [28] & 207 & AAAP & 36 & $99.1 \%$ & $5.8 \%$ & $\begin{array}{l}2.1 \% / 2.1 \% / 3.1 \%(1 / 2 / \\
3 \text { years) }\end{array}$ & NA \\
\hline Uehara et al. [39] & 36 & AAAP & 31.8 & $100 \%$ & $7 \%$ & $0 \%$ & NA \\
\hline Current study & 138 & AAAP & 25.1 & $89.5 \%$ & $18.4 \%$ & $28.1 \%$ & $\begin{array}{l}100 \% / 97.2 \% / 89.7 \%(6 / \\
12 / 24 \text { months })\end{array}$ \\
\hline
\end{tabular}

$A A A P$ artificial ascites/artificial pleural effusion, $H C C$ hepatocellular carcinoma, $N A$ not available, $T E$ technique effectiveness, $L T P$ local tumor progression, $H R$ high-risk

complete ablation outweighed the low rate of electrode tract seeding. Complete ablation was achieved in $89.5 \%$ (68/76) in the AAAP group versus $76.5 \%$ (91/119) in the non-AAAP group. The modestly higher rate of technical effectiveness in prior studies can potentially be explained by a greater number of treatment sessions and smaller tumor size in their cohort [17, 18, 28, 39].

The factors associated with local tumor progression were tumor size and failure to achieve complete ablation. In the present study, local tumor progression rate in the AAAP group was $28.1 \%$. This exclusively involved treatment-naïve nodules with a median follow-up of 21.5 months. Large variations in the reported rates of tumor progression after RFA to tumors in high-risk locations from 2.1 to $76 \%$ can be attributable to the heterogeneity of median follow-up period, sample population, and non-standardization of reporting criteria (Table 6). In previous studies, subcapsular tumors and tumors abutting hollow viscera were associated with higher local tumor progression rate because of the inability to achieve a $0.5-1.0 \mathrm{~cm}$ tumor free margin $[35,36]$.

Tumor characteristics and hepatic functional reserve are essential features as prognostic indices for HCC [40]. In addition to these well-established factors, technical parameters during RFA have been demonstrated to affect patient's survival for HCC in high-risk locations. With the adoption of this strategy, survival rates of HCC in high-risk locations have been reported to be compatible to that of non-high-risk locations and patients who underwent surgical resection $[19,41,42]$. This impact is crucial for resection of HCC in high-risk locations to avoid post-operative liver failure. 
There are two limitations in out study. Firstly, we acknowledged that a definite benefit of artificial intraperitoneal and intrapleural creation can only be demonstrated in a large randomized controlled study. However it is probably ethically unfeasible since these were already perceived as practical means of safety and effectiveness based on initial studies [2, 6, 16-19, 28]. Secondly, comparison between non-AAAP and AAAP groups was not concurrent, and the AAAP cohort occurred subsequent to all non-AAAP patients. Some level of change in survival could be attributed to the improved medical care for liver disease over the different time periods. It was also possible that experience from the non-AAAP era contributed to improved outcomes of the AAAP era.

The further approaches such as complementary use of contrast-enhanced ultrasound and real-time virtual sonography to overcome insufficient visualization by gray-scale sonography and improve overall visualization of inconspicuous tumors can be recommended [43-45]. Employment of multipolar RF electrodes and the influence of combined loco-regional therapy in large unresectable HCC in special locations will play a crucial role in the improvement of technical and clinical effect [46-48]. Prospective comparison of clinical outcomes between percutaneous RFA with AAAP creation and laparoscopic and surgical approaches is another area for future investigation.

In conclusion, HCC in high-risk locations pose a challenge in the area of radio-ablative therapeutic modalities. With the advent of AA and AP creation, survival of patients with HCC in high-risk locations has significantly increased as a consequence of reducing anatomical restrictions to percutaneous RFA, expanding patient's eligibility using a minimally invasive strategy without jeopardizing the primary technique effectiveness and precluding patient's exposure to the potential risks inherent to laparoscopic and surgical approaches. The effort of refining methodological protocols to meet the challenges of RFA aids in the prevention of procedure-related complications and improves proficiency and competence of interventional hepatologists in this center. This study has demonstrated that a paradigm shift in the practice of RFA reduces complications and improves survival in patients with HCC in high-risk locations. Its application in high-risk located tumors could be greatly advocated.

\section{Compliance with ethical standards}

Conflict of interest All authors declared that they have no competing interests.
Open Access This article is distributed under the terms of the Creative Commons Attribution 4.0 International License (http://creative commons.org/licenses/by/4.0/), which permits unrestricted use, distribution, and reproduction in any medium, provided you give appropriate credit to the original author(s) and the source, provide a link to the Creative Commons license, and indicate if changes were made.

\section{Appendix}

\section{Grading of the therapy-oriented severity grading system}

Grade 1: no need for specific intervention

Grade 2: need for drug therapy

Grade 3a: need for invasive therapy without general anesthesia

Grade 3b: invasive therapy under general anesthesia

Grade 4a: single organ dysfunction (including dialysis) with ICU stay

Grade 4b: multi-organ dysfunction requiring ICU management

Grade 5: death

\section{References}

1. Kokudo N, Hasegawa K, Akahane M, Igaki H, Izumi N, Ichida T, et al. (2015) Evidence-based Clinical Practice Guidelines for Hepatocellular Carcinoma: The Japan Society of Hepatology 2013 update (3rd JSH-HCC Guidelines). Hepatology research: the official journal of the Japan Society of Hepatology. https:// doi.org/10.1111/hepr.12464.

2. European Association for the Study of the Liver. Electronic address eee, European Association for the Study of the L. EASL Clinical Practice Guidelines: Management of hepatocellular carcinoma. Journal of hepatology. 2018. https://doi.org/10.1016/j. jhep.2018.03.019

3. Bruix J, Sherman M (2011) Management of hepatocellular carcinoma: an update. Hepatology (Baltimore, Md). 53(3):1020-1022. https://doi.org/10.1002/hep.24199

4. Omata M, Cheng AL, Kokudo N, et al. (2017) Asia-Pacific clinical practice guidelines on the management of hepatocellular carcinoma: a 2017 update. Hepatology international. 11(4):317-370. https://doi.org/10.1007/s12072-017-9799-9

5. Forner A, Reig M, Bruix J (2018) Hepatocellular carcinoma. Lancet (London, England). 391(10127):1301-1314. https://doi. org/10.1016/s0140-6736(18)30010-2

6. Management consensus guideline for hepatocellular carcinoma (2018) 2016 updated by the Taiwan Liver Cancer Association and the Gastroenterological Society of Taiwan. J Formos Med Assoc. 117(5):381-403. https://doi.org/10.1016/j.jfma.2017.09.007

7. Livraghi T, Meloni F, Di Stasi M, et al. (2008) Sustained complete response and complications rates after radiofrequency ablation of very early hepatocellular carcinoma in cirrhosis: Is resection still the treatment of choice? Hepatology (Baltimore, Md). 47(1):82-89. https://doi.org/10.1002/hep.21933 
8. Lin S-M, Lin C-J, Lin C-C, Hsu C-W, Chen Y-C (2004) Radiofrequency ablation improves prognosis compared with ethanol injection for hepatocellular carcinoma $\leq 4 \mathrm{~cm}$. Gastroenterology. 127(6):1714-1723. https://doi.org/10.1053/j.gas tro.2004.09.003

9. Lin SM, Lin CJ, Lin CC, Hsu CW, Chen YC (2005) Randomised controlled trial comparing percutaneous radiofrequency thermal ablation, percutaneous ethanol injection, and percutaneous acetic acid injection to treat hepatocellular carcinoma of $3 \mathrm{~cm}$ or less. Gut. 54(8):1151-1156. https://doi.org/10.1136/gut.2004.045203

10. Shiina S, Teratani T, Obi S, et al. (2005) A Randomized Controlled Trial of Radiofrequency Ablation With Ethanol Injection for Small Hepatocellular Carcinoma. Gastroenterology. 129(1):122-130. https://doi.org/10.1053/j.gastro.2005.04.009

11. Lencioni RA, Allgaier HP, Cioni D, et al. (2003) Small hepatocellular carcinoma in cirrhosis: randomized comparison of radiofrequency thermal ablation versus percutaneous ethanol injection. Radiology. 228(1):235-240. https://doi.org/10.1148/radiol. 2281020718

12. Koda M, Ueki M, Maeda N, Murawaki Y (2003) Diaphragmatic perforation and hernia after hepatic radiofrequency ablation. AJR American journal of roentgenology. 180(6):1561-1562. https:// doi.org/10.2214/ajr.180.6.1801561

13. Kim YS, Rhim H, Sung JH, et al. (2005) Bronchobiliary fistula after radiofrequency thermal ablation of hepatic tumor. Journal of vascular and interventional radiology: JVIR. 16(3):407-410. https://doi.org/10.1097/01.rvi.0000150034.77451.6f

14. Mulier S, Mulier P, Ni Y, et al. (2002) Complications of radiofrequency coagulation of liver tumours. The British journal of surgery. 89(10):1206-1222. https://doi.org/10.1046/j.13652168.2002.02168.x

15. Livraghi T, Solbiati L, Meloni MF, et al. (2003) Treatment of focal liver tumors with percutaneous radio-frequency ablation: complications encountered in a multicenter study. Radiology. 226(2):441-451. https://doi.org/10.1148/radiol.2262012198

16. Koda M, Ueki M, Maeda Y, et al. (2004) Percutaneous sonographically guided radiofrequency ablation with artificial pleural effusion for hepatocellular carcinoma located under the diaphragm. AJR American journal of roentgenology 183(3):583-588. https://doi.org/10.2214/ajr.183.3.1830583

17. Rhim H, Lim HK, Kim YS, Choi D (2008) Percutaneous radiofrequency ablation with artificial ascites for hepatocellular carcinoma in the hepatic dome: initial experience. AJR American journal of roentgenology. 190(1):91-98. https://doi.org/10.2214/ ajr.07.2384

18. Kondo Y, Yoshida H, Shiina S, et al. (2006) Artificial ascites technique for percutaneous radiofrequency ablation of liver cancer adjacent to the gastrointestinal tract. The British journal of surgery. 93(10):1277-1282. https://doi.org/10.1002/bjs.5374

19. Kondo Y, Yoshida H, Tateishi R, et al. (2008) Percutaneous radiofrequency ablation of liver cancer in the hepatic dome using the intrapleural fluid infusion technique. The British journal of surgery. 95(8):996-1004. https://doi.org/10.1002/bjs.6058

20. Wong SN, Lin CJ, Lin CC, et al. (2008) Combined percutaneous radiofrequency ablation and ethanol injection for hepatocellular carcinoma in high-risk locations. AJR American journal of roentgenology. 190(3):W187-W195. https://doi.org/10.2214/ajr. 07.2537

21. Macatula TC, Lin CC, Lin CJ, Chen WT, Lin SM (2012) Radiofrequency ablation for hepatocellular carcinoma: use of low vs maximal radiofrequency power. The British journal of radiology. 85(1014):e102-e109. https://doi.org/10.1259/bjr/ 85505073

22. Tsoumakidou G, Buy X, Garnon J, Enescu J, Gangi A (2011) Percutaneous thermal ablation: how to protect the surrounding organs. Techniques in vascular and interventional radiology. 14(3):170-176. https://doi.org/10.1053/j.tvir.2011.02.009

23. Sato M, Watanabe Y, Tokui K, et al. (2000) CT-guided treatment of ultrasonically invisible hepatocellular carcinoma. The American journal of gastroenterology. 95(8):2102-2106. https://doi.org/10. 1111/j.1572-0241.2000.02275.x

24. Simo KA, Sereika SE, Newton KN, Gerber DA (2011) Laparoscopic-assisted microwave ablation for hepatocellular carcinoma: safety and efficacy in comparison with radiofrequency ablation. Journal of surgical oncology. 104(7):822-829. https://doi.org/10. $1002 /$ jso. 21933

25. Cassera MA, Potter KW, Ujiki MB, Swanstrom LL, Hansen PD (2011) Computed tomography (CT)-guided versus laparoscopic radiofrequency ablation: a single-institution comparison of morbidity rates and hospital costs. Surgical endoscopy 25(4):1088-1095. https://doi.org/10.1007/s00464-010-1322-5

26. Berber E, Siperstein A (2008) Local recurrence after laparoscopic radiofrequency ablation of liver tumors: an analysis of 1032 tumors. Annals of surgical oncology. 15(10):2757-2764. https:// doi.org/10.1245/s10434-008-0043-7

27. Lin SM (2013) Local ablation for hepatocellular carcinoma in taiwan. Liver cancer. 2(2):73-83. https://doi.org/10.1159/000343843

28. Teratani T, Yoshida H, Shiina S, et al. (2006) Radiofrequency ablation for hepatocellular carcinoma in so-called high-risk locations. Hepatology (Baltimore, Md). 43(5):1101-1108. https:// doi.org/10.1002/hep.21164

29. Edmondson HA, Steiner PE (1954) Primary carcinoma of the liver: a study of 100 cases among 48,900 necropsies. Cancer. 7(3):462-503

30. Lin SM, Lin CJ, Chung HJ, Hsu CW, Peng CY (2003) Power rolloff during interactive radiofrequency ablation can enhance necrosis when treating hepatocellular carcinoma. AJR American journal of roentgenology. 180(1):151-157. https://doi.org/10. 2214/ajr.180.1.1800151

31. Ahmed M, Solbiati L, Brace CL, et al. (2014) Image-guided tumor ablation: standardization of terminology and reporting criteria-a 10-year update. Radiology. 273(1):241-260. https:// doi.org/10.1148/radiol.14132958

32. Saad WE, Wallace MJ, Wojak JC, Kundu S, Cardella JF (2010) Quality improvement guidelines for percutaneous transhepatic cholangiography, biliary drainage, and percutaneous cholecystostomy. Journal of vascular and interventional radiology: JVIR. 21(6):789-795. https://doi.org/10.1016/j.jvir.2010.01.012

33. Dindo D, Demartines N, Clavien PA (2004) Classification of surgical complications: a new proposal with evaluation in a cohort of 6336 patients and results of a survey. Annals of surgery. 240(2):205-213

34. Machi J, Uchida S, Sumida K, et al. (2001) Ultrasound-guided radiofrequency thermal ablation of liver tumors: percutaneous, laparoscopic, and open surgical approaches. Journal of gastrointestinal surgery: official journal of the Society for Surgery of the Alimentary Tract. 5(5):477-489 (Epub 2002/05/03 PubMed PMID: 11985998)

35. Komorizono Y, Oketani M, Sako K, et al. (2003) Risk factors for local recurrence of small hepatocellular carcinoma tumors after a single session, single application of percutaneous radiofrequency ablation. Cancer. 97(5):1253-1262. https://doi.org/10.1002/cncr. 11168

36. Hori T, Nagata K, Hasuike S, et al. (2003) Risk factors for the local recurrence of hepatocellular carcinoma after a single session of percutaneous radiofrequency ablation. $\mathrm{J}$ Gastroenterol. 38(10):977-981. https://doi.org/10.1007/s00535-003-1181-0

37. Knuttinen M-G, Van Ha T, Reilly C, Montag A, Straus C (2014) Unintended Thermal Injuries from Radiofrequency Ablation: Organ Protection with an Angioplasty Balloon Catheter in an 
Animal Model. Journal of Clinical Imaging Science. 4(1):1. https://doi.org/10.4103/2156-7514.126018

38. Llovet JM, Vilana R, Bru C, et al. (2001) Increased risk of tumor seeding after percutaneous radiofrequency ablation for single hepatocellular carcinoma. Hepatology (Baltimore, Md). 33(5):1124-1129. https://doi.org/10.1053/jhep.2001.24233

39. Uehara T, Hirooka M, Ishida K, et al. (2007) Percutaneous ultrasound-guided radiofrequency ablation of hepatocellular carcinoma with artificially induced pleural effusion and ascites. J Gastroenterol. 42(4):306-311. https://doi.org/10.1007/s00535006-1949-0

40. Llovet JM, Bru C, Bruix J (1999) Prognosis of hepatocellular carcinoma: the BCLC staging classification. Semin Liver Dis 19(3):329-338. https://doi.org/10.1055/s-2007-1007122

41. Poon RT, Fan ST, Lo CM, Liu CL, Wong J (2002) Long-term survival and pattern of recurrence after resection of small hepatocellular carcinoma in patients with preserved liver function: implications for a strategy of salvage transplantation. Annals of surgery. 235(3):373-382

42. Nagasue N, Yukaya H (1989) Liver resection for hepatocellular carcinoma: results from 150 consecutive patients. Cancer chemotherapy and pharmacology 23(Suppl):S78-S82

43. Kim SH, Lee JM, Lee JY, et al. (2005) Value of contrast-enhanced sonography for the characterization of focal hepatic lesions in patients with diffuse liver disease: receiver operating characteristic analysis. AJR American journal of roentgenology 184(4):1077-1084. https://doi.org/10.2214/ajr.184.4.01841077

44. Park HS, Kim YJ, Yu MH, Jung SI, Jeon HJ (2015) Real-time contrast-enhanced sonographically guided biopsy or radiofrequency ablation of focal liver lesions using perflurobutane microbubbles (sonazoid): value of Kupffer-phase imaging. Journal of ultrasound in medicine: official journal of the American Institute of Ultrasound in Medicine 34(3):411-421. https://doi. org/10.7863/ultra.34.3.411
45. Lee C-H, Chen W-T, Lin C-C, et al. (2015) Radiofrequency ablation assisted by real-time virtual sonography for hepatocellular carcinoma inconspicuous under sonography and high-risk locations. The Kaohsiung journal of medical sciences 31(8):413-419. https://doi.org/10.1016/j.kjms.2015.06.002

46. Seror O, N'Kontchou G, Ibraheem M, et al. (2008) Large $(>$ or $=5.0-\mathrm{cm}$ ) HCCs: multipolar RF ablation with three internally cooled bipolar electrodes-initial experience in 26 patients. Radiology 248(1):288-296. https://doi.org/10.1148/radiol. 2481071101

47. Lin CC, Cheng YT, Chen MWT, Lin S-M (2016) The Effectiveness of Multiple Electrode Radiofrequency Ablation in Patients with Hepatocellular Carcinoma with Lesions More than $3 \mathrm{~cm}$ in Size and Barcelona Clinic Liver Cancer Stage A to B2. Liver cancer. 5(1):8-20. https://doi.org/10.1159/000367755

48. Wang X, Hu Y, Ren M, et al. (2016) Efficacy and Safety of Radiofrequency Ablation Combined with Transcatheter Arterial Chemoembolization for Hepatocellular Carcinomas Compared with Radiofrequency Ablation Alone: A Time-to-Event MetaAnalysis. Korean J Radiol 17(1):93-102

49. Chen MH, Yang W, Yan K, et al. (2008) Radiofrequency ablation of problematically located hepatocellular carcinoma: tailored approach. Abdominal imaging. 33(4):428-436. https://doi.org/10. 1007/s00261-007-9283-4

50. Kang TW, Lim HK, Lee MW, et al. (2013) First-line radiofrequency ablation with or without artificial ascites for hepatocellular carcinomas in a subcapsular location: local control rate and risk of peritoneal seeding at long-term follow-up. Clinical radiology 68(12):e641-e651. https://doi.org/10.1016/j.crad.2013.07. 008

51. Nam SY, Rhim H, Kang TW, et al. (2010) Percutaneous radiofrequency ablation for hepatic tumors abutting the diaphragm: clinical assessment of the heat-sink effect of artificial ascites. AJR American journal of roentgenology 194(2):W227W231. https://doi.org/10.2214/ajr.09.2979 